\title{
Research of AHP/DEA evaluation model for operation performance of municipal wastewater treatment plants
}

\author{
Zhang Xiaoxin ${ }^{1}$, Huang Jin ${ }^{1, *}$, Lin Ling ${ }^{1}$, Wang Yueping ${ }^{2}$, Zhang Xinheng ${ }^{2}$ \\ ${ }^{1}$ China National Institute of Standardization, 100191 Beijing, China \\ ${ }^{2}$ MCC HUATIAN Engineering \& Technology Corporation, 243011 Ma'anshan, China
}

\begin{abstract}
The operation performance evaluation of municipal wastewater treatment plants is an extremely important and complex issue in the management of wastewater treatment plants. Based on constructing the operation performance evaluation index system of the municipal wastewater treatment plant in China, according to the characteristics of the analytic hierarchy process (AHP) and the data envelopment method (DEA), a comprehensive evaluation model combining AHP/DEA was established to evaluate the operation performance of the municipal wastewater treatment plants in China. AHP/DEA comprehensive evaluation model fully considers the subjective and objective factors with effectiveness and scientific nature.
\end{abstract}

\section{Introduction}

The municipal wastewater treatments and recycling facilities, as the important guarantee for the economic development and safe healthy living of the residents, are indispensable infrastructure for municipal development. During "13th Five-Year Plan", China further integrated the planning and increased the investment to transform the municipal wastewater treatment facilities from "scale growth" to "quality and efficiency improvement", from "focusing on water and ignoring sludge" to "focusing on both water and sludge", from "wastewater treatment" to "recycling", comprehensively improving the guarantee ability and service of municipal wastewater treatment facilities domestically.

At present, the concept of wastewater treatment in some cities has just accomplished the transformation from "focusing on the wastewater treatment volume" to "pursuing the wastewater treatment quality". As the centralized control unit of the pollutants, the municipal wastewater treatment plant plays an important role in the strategy of pollutant emission reduction in China. In order to take full advantage of the existing facilities of the wastewater treatment plants and improve the operation and management of the municipal wastewater treatment plant, it is urgent to strengthen the evaluation of the operation performance of the wastewater treatment plant.

\section{Construction of the operation} performance evaluation index system for municipal wastewater treatment plants

\subsection{Design principles of operation performance evaluation index system for municipal wastewater treatment plants}

The evaluation index system based on Globerson's theory [1], and combining the operating characteristics and actual conditions of the municipal wastewater treatment plants in China, the following basic principles was proposed when designing the evaluation index system of the operation performance of the municipal wastewater treatment plants:

(1) Purposiveness. The operation performance evaluation index system of municipal wastewater treatment plant should accurately measure the operation status of the municipal wastewater treatment plant as well as find the bottleneck of low operation performance, therefore, the improvement method and improve the operation performance of the municipal wastewater treatment plant can be figured out.

(2) Systematicness. The municipal wastewater treatment plant has complex processing technology. The operation evaluation index system should be able to reflect the operation performance of each processing technology in a comprehensive, systematic and complete way from multiple views.

(3) Scientificalness. The index should be scientific and reasonable, concise and feasible. It can accurately reflect the actual operation of the municipal wastewater treatment plant, and help the enterprises explore the potential of competition by comparing their own evaluation indexes with the competitors at home and abroad.

(4) Feasibility. The index should be measurable and comparable, with simple calculation method, and the data should be easily accessed.

\footnotetext{
* Corresponding author: huangjin@cnis.gov.cn
} 
(5) Combination of quantitative and qualitative. The operation performance of municipal wastewater treatment plant is an abstract concept. The quantitative and qualitative index should be comprehensively considered in the evaluation. The qualitative index should have clear meaning with appropriate assignment, so that they can accurately reflect the nature of index; the calculation method should be provided for the quantitative index.

(6) Dynamics. The index system should reflect the present situation and the future trend of the municipal wastewater treatment industry for easy prediction and decision-making. At the same time, the index system content should be relatively stable within a certain period.

\subsection{Operation performance evaluation index system of municipal wastewater treatment plants}

Based on the principles mentioned above, the operation evaluation index system of municipal wastewater treatment plant is established consisting of 23 indexes in five categories at three levels as shown in Table 1.

Table 1. Operation evaluation index system for municipal wastewater treatment plant

\begin{tabular}{|c|c|c|}
\hline $\begin{array}{l}\text { Target } \\
\text { layer }\end{array}$ & $\begin{array}{l}\text { Class I index } \\
\text { layer }\end{array}$ & Class II index layer \\
\hline \multirow{20}{*}{$\begin{array}{l}\text { Operation } \\
\text { evaluation } \\
\text { of } \\
\text { municipal } \\
\text { wastewater } \\
\text { treatment } \\
\text { system A }\end{array}$} & \multirow{5}{*}{$\begin{array}{l}\text { Environment } \\
\text { al protection } \\
\text { performance } \\
\text { B1 }\end{array}$} & $\begin{array}{l}\text { Average annual water } \\
\text { quality compliance rate } \mathrm{C} 1\end{array}$ \\
\hline & & $\begin{array}{l}\text { Annual average } \\
\text { atmospheric compliance } \\
\text { rate } \mathrm{C} 2\end{array}$ \\
\hline & & $\begin{array}{l}\text { Average annual sludge } \\
\text { quality compliance rate C3 }\end{array}$ \\
\hline & & $\begin{array}{l}\text { Comprehensive reduction } \\
\text { rate of annual average } \\
\text { pollutant } \mathrm{C} 4\end{array}$ \\
\hline & & $\ldots$ \\
\hline & \multirow{3}{*}{$\begin{array}{l}\text { Resource and } \\
\text { energy } \\
\text { consumption } \\
\text { B2 }\end{array}$} & $\begin{array}{l}\text { Power consumption per } \\
\text { unit treated water C5 }\end{array}$ \\
\hline & & $\begin{array}{l}\text { Drug consumption per unit } \\
\text { treated waterC6 }\end{array}$ \\
\hline & & $\begin{array}{l}\text { Fresh water consumption } \\
\text { per unit treated waterC7 }\end{array}$ \\
\hline & \multirow{6}{*}{$\begin{array}{l}\text { Technical } \\
\text { and } \\
\text { economic } \\
\text { performance } \\
\text { B3 }\end{array}$} & $\begin{array}{l}\text { Technical performance } \\
\text { requirements } \mathrm{C} 8 *\end{array}$ \\
\hline & & $\begin{array}{l}\text { Operation cost per unit } \\
\text { treated water } \mathrm{C} 9\end{array}$ \\
\hline & & $\begin{array}{l}\text { Annual power } \\
\text { consumption per unit COD } \\
\text { C10 }\end{array}$ \\
\hline & & $\begin{array}{l}\text { Annual maintenance cost } \\
\mathrm{C} 11\end{array}$ \\
\hline & & Annual labor cost $\mathrm{C} 12$ \\
\hline & & \\
\hline & \multirow{6}{*}{$\begin{array}{l}\text { Operational } \\
\text { management } \\
\text { B4 }\end{array}$} & System and rules $\mathrm{C} 13^{*}$ \\
\hline & & Personnel training $\mathrm{C} 14^{*}$ \\
\hline & & Emergency plan C15* \\
\hline & & Operation and record $\mathrm{C} 16^{*}$ \\
\hline & & $\begin{array}{l}\text { Monitoring analysis record } \\
\mathrm{C} 17^{*}\end{array}$ \\
\hline & & $\ldots$ \\
\hline
\end{tabular}

\begin{tabular}{|c|c|c|}
\hline \multirow{7}{*}{ 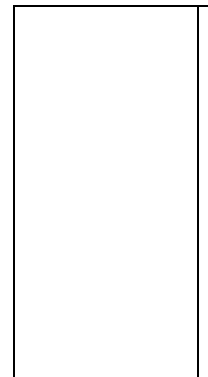 } & \multirow{7}{*}{$\begin{array}{l} \\
\text { Key } \\
\text { equipment } \\
\text { status B5 }\end{array}$} & Annual operation rate $\mathrm{C} 18$ \\
\hline & & Operation water load C19 \\
\hline & & Operation COD load C20 \\
\hline & & $\begin{array}{l}\text { Construction completion } \\
\text { rate } \mathrm{C} 21\end{array}$ \\
\hline & & $\begin{array}{l}\text { Key equipment integrity } \\
\text { rate C22 }\end{array}$ \\
\hline & & $\begin{array}{l}\text { Key equipment } \\
\text { advancement } \mathrm{C} 23 *\end{array}$ \\
\hline & & $\ldots$ \\
\hline
\end{tabular}

Note: * indicates that the index is a qualitative evaluation index

\section{Common performance evaluation model principles}

\subsection{Analytic Hierarchy Process, AHP}

Analytic hierarchy process (AHP) is a simple practical multi-objective decision analysis method [2], proposed by Saaty $\cdot \mathrm{T} \cdot \mathrm{L}$, American operational research experts in 1970s. It quantifies the qualitative problems by prioritization of all the solutions and the judgment made by the experienced people (e.g. experts) to simply and clarifies the complicated problems. It is widely used in the production decision-making, education, medicine, agriculture, economy, and security fields. The analytic hierarchy process must firstly clarify the problem to be solved, and then simplify it into an ordered multi-level structure; ultimately it corresponds to multiple solutions [3]. After analyzing the essence, influence factors and internal relations of the complex problems, AHP constructs the hierarchical structure model of the problem, and then uses less quantitative information to mathematically transform the decision-making process to solve the complex problem decision making with multi-objective, multi criteria or unstructured characteristics. The basic steps are:

(1) The hierarchical structure of the system should be established, and the relationship between the factors in the system should be analyzed. Then the comprehensive evaluation of multiple indexes and multi-objective decision-making problems need to be identified, as well as the problem scope, the included factors and the relationship between them. The hierarchical structure system is divided into: 1) highest level; 2) the middle level; 3) the lowest level. The level division should be reasonable and objective. The upper factors can determine the lower factors, and the lower factors are subordinate to the upper tier.

(2) Pairwise comparison for the importance of each element on the same level about a certain criterion in the upper level should be performed while pairwise comparison judgment matrix should be constructed. For several elements, the pairwise comparison judgment matrix can be obtained in the appropriate scale (generally using 1-9 scale method).

$$
\mathrm{A}=\left(\mathrm{a}_{\mathrm{ij}}\right)(\mathrm{n} \times \mathrm{n})
$$

Among them, $a$ is the importance of factor $i$ compared to factor $\mathrm{j}$ according to a certain criterion; and: $a_{i j}>0 ; \quad a_{i j}=1 / a_{j i} ; \quad a_{i i}=1(i, j=1,2, \ldots, n)$. 
(3) The relative weight of the comparison element is calculated by the judgment matrix. The consistency check is made. The arithmetic mean method, the geometric mean method, the eigenvalue method, the least square method, and the logarithm least square method are commonly used to calculate the weight and the least deviation method (LDM), the gradient eigenvector method (GEM) and the generalized eigenvalue method are also used. The generalized eigenvalue method has been widely used: the maximum eigenvalues and the eigenvalues direction of the arbitrary precision can be obtained by the root method, the sum product method or the power method. The eigenvectors represent the weight of the influence of each factor at this level to some factor at upper level: $\mathrm{W}=(\omega 1, \omega 2$, $\omega 3, \ldots, \omega n)$. Since the judgment matrix element is assigned by person, it will have deviation, so consistency test is needed to evaluate the reliability of the judgment matrix. It is necessary to calculate the ratio of consistency:

$$
\text { C.R. }=\text { C.I./R.I. }
$$

$\lambda \max =\frac{1}{n} \sum_{i=1}^{n}\left[\left(A \omega_{i}\right) / \omega_{i}\right]=\frac{1}{2} \sum_{i=1}^{n}\left[\left(\sum_{j=1}^{n} a_{i j} \omega_{i}\right) / \omega_{i}\right]$

Where: C.I. $=(\lambda \max -n) / \mathrm{n}-1 ; \lambda \max$ is the maximum eigenvalue of the judgment matrix; $n$ is the judgment matrix order; R.I. is the average random consistency index, which can be found in Table 2. When C.I. $<0.1$, it is considered that the consistency of the judgment matrix is acceptable; when C.I. $\geq 0.1$, the judgment matrix shall be corrected appropriately.

Table 2 Average random consistency index

\begin{tabular}{llllllll}
\hline Order & 1 & 2 & 3 & 4 & 5 & 6 & 7 \\
\hline R.I. & 0 & 0 & 0.58 & 0.89 & 1.12 & 1.26 & 1.36 \\
\hline & & & & & & & \\
\hline Order & 8 & 9 & 10 & 11 & 12 & 13 & 14 \\
\hline R.I. & 1.41 & 1.42 & 1.49 & 1.52 & 1.54 & 1.56 & 1.58 \\
\hline
\end{tabular}

(4) Calculate the combination weight of elements at each level to the total target of the system and prioritize them. Synthesize the element weight at single level from bottom to top to calculate the relative weight of each element to the total target. In particular, the combination weight of the lowest level factor to the highest level. It is assumed that the weight vector W1k-1 of total target of the $\mathrm{n}_{\mathrm{k}-1}$ element on level $\mathrm{k}-1$ is calculated: the element weight vector $\mathrm{j}$ on level $\mathrm{k}-1$ of the $\mathrm{n}_{\mathrm{k}}$ elements on level $\mathrm{k}$ is $\mathrm{W}_{\mathrm{j}}(\mathrm{k})=\left(\mathrm{W}_{1 \mathrm{j}}(\mathrm{k}), \mathrm{W}_{2 \mathrm{j}}(\mathrm{k}), \ldots, \mathrm{W}_{\mathrm{nk}}(\mathrm{k})\right) \mathrm{T}$. Where, the element weight vector not assigned by $\mathrm{j}$ is zero. So: $\mathrm{W}_{\mathrm{j}}{ }^{(\mathrm{k}-}$ ${ }^{1)}=\left(\mathrm{W}_{1}{ }^{(\mathrm{k})}, \mathrm{W}_{2}{ }^{(\mathrm{k})}, \ldots, \mathrm{W}_{\mathrm{nk}-1}{ }^{(\mathrm{k})}\right)$ indicates the assignment weight of element at level $\mathrm{k}-1$ on level $\mathrm{k}$, so the combined weight vector of the total target on level $\mathrm{k}$ is:

$$
\mathrm{W}_{\mathrm{k}}^{\mathrm{k}-1}=\mathrm{W}_{\mathrm{k}}^{\mathrm{k}-1} \cdot \mathrm{W}_{\mathrm{k}-1}{ }^{\mathrm{k}}
$$

The data envelopment analysis (DEA) is an effective efficiency evaluation method proposed by American operational research experts Chanes.A and W.W.Cooper [4]. It performs the multi-target evaluation and prioritization for the decision-making units from the relative effectiveness. It can process the non-parametric analysis method for multiple inputs and multiple outputs. The basic principle is to regard each unit as a decision making unit (Decision Making Units, DMU), and then multiple DMUs compose of group to be evaluated, and it is assumed several DMUs is available. Each DMU has $\mathrm{m}$ type input (resource consumption) and $S$ type output (effective information). Each decision making units $\mathrm{j}$ $(j=1,2, \ldots, n)$ corresponds to an input vector $X_{j}=\left(x_{1 j}\right.$, $\left.\mathrm{x}_{2 \mathrm{j}}, \ldots, \mathrm{x}_{\mathrm{mj}}\right) \mathrm{T}$ and an output vector $\mathrm{Y}_{\mathrm{j}}=\left(\mathrm{y}_{1 \mathrm{j}}, \mathrm{y}_{2 \mathrm{j}}, \ldots\right.$, $\left.y_{s j}\right) T . x_{i j}$ is the total amount of type $j$ decision making unit to type $\mathrm{i}$ input, $\mathrm{x}_{\mathrm{ij}}>0 ; \mathrm{y}_{\mathrm{rj}}$ is the total output type $\mathrm{j}$ decision making unit to type $r$ output, $y_{r j}>0 ; i=1,2, \ldots$, $\mathrm{m} ; \mathrm{j}=1,2, \ldots, \mathrm{m} ; \mathrm{r}=1,2, \ldots, \mathrm{s}$. It can construct effective linear planning model for DEA inputs and outputs for the decision making unit $\mathrm{i}$ :

$$
\begin{aligned}
& \min \theta=V D \\
& \text { s.t. } \\
& \sum_{j=1}^{n} \lambda_{j} X_{j} \leq \theta X_{j 0} \\
& \quad \sum_{j=1}^{n} \lambda_{j} Y_{j} \geq Y_{j 0}
\end{aligned}
$$

Where $\lambda j>0 ; j=1,2, \ldots, n$. With slack variable introduced, the model can be written as:

$$
\begin{gathered}
\min \{\theta\} \\
\text { s.t. } \sum_{j=1}^{\mathrm{n}} \lambda_{\mathrm{j}} \mathrm{X}_{\mathrm{j}}+\mathrm{S}^{-}=\theta \mathrm{X}_{\mathrm{j} 0} \\
\sum_{\mathrm{j}=1}^{\mathrm{n}} \lambda_{\mathrm{j}} \mathrm{Y}_{\mathrm{j}}-\mathrm{S}^{+}=\mathrm{Y}_{\mathrm{j} 0} \\
\lambda \mathrm{j} \geq 0 ; \mathrm{S}-\geq 0 ; \mathrm{S}+\geq 0 ; \theta \text { free variables }
\end{gathered}
$$

Among them: $\mathrm{Xj} 0$ is the $\mathrm{j} 0$ input index vector; $\mathrm{Y}_{\mathrm{j} 0}$ is the $\mathrm{j} 0$ output index vector; $\theta$ is the input reduction ratio; $\lambda \mathrm{j}$ is the coefficient of the linear combination of the decision making unit; $\mathrm{S}^{-}$and $\mathrm{S}^{+}$are slack variables. DMUj0 is sufficient and necessary condition for DEA. It is the optimal value $\mathrm{VD}=1$ of the planning problem above. Each optimal solution has $(*$ indicates the optimal solution.): $\lambda^{*}, \mathrm{~S}^{*-}, \mathrm{S}^{{ }^{*+}} ; \theta$ has $\mathrm{S}^{*_{-}}=0, \mathrm{~S}^{*+}=0$. Validity analysis: if $\theta^{*}=1, \mathrm{~S}^{*}=\mathrm{S}^{*+}=0$, then $\mathrm{j} 0$ unit is DEA effective; if $\theta^{*}=1, \mathrm{~S}^{*-}$ and $\mathrm{S}^{*+}$ have non-zero values, the j0 unit is called the DEA weak effect; if $\theta^{*}<1, \mathrm{j} 0$ unit is invalid.

\section{Analytic hierarchy process (AHP)/data envelopment analysis (DEA) evaluation model for operation effect of municipal wastewater treatment plants}




\subsection{Application of analytic hierarchy process (AHP) and data envelopment analysis (DEA) in domestic and overseas research}

AHP method is an effective method to transform the semi-qualitative and semi-quantitative problems into the quantitative calculation. It can fully reflect the preference of the decision-makers and quantify the experience of the decision-makers. It provides the decision makers with the decision-making basis in quantitative form to fully reflect the subjective factors of evaluation. The DEA method doesn't require estimating the parameters in advance and making thorough understanding to the information structure of the output and input quantity. The weight of the input and output index of each decision making unit is the variable to avoid the weight determination of each index in the priority meaning, less influenced by the uncertain subjective factors, reflecting the objectivity of the evaluation results, with advantages to avoid the subjective factors, simplify the calculation and reduce the errors. Thus it has application prospects in multiobjective evaluation. Therefore, in the multiple index and multi-target comprehensive evaluation and multiobjective decision-making, AHP method is integrated with DEA method. To take full advantage of their respective advantages, considering the subjective and objective factors and reduce the gap between the subjective and objective realities, the evaluation method is improved and the result of evaluation is more scientific. The combination of DEA and AHP methods not only compensates the randomness of the DEA selection evaluation index, but also improves the scientific nature when selecting the evaluation index, and reduces the subjectivity when setting the AHP weight and the evaluation system combining the two methods is more scientific.

At present, there are several researches on the model application combining the two methods in performance evaluation at home and abroad. Jyoti et al. used the DEA-AHP model to assess and compare the performance of the India National Research and Development Organization. The research found that the relative efficiency of the National Research and Development Organization is not only based on the quantity output, but also based on the output and quality, and provides a more comprehensive and real results to the decision-makers [5]. Yang et al. took the property insurance company, China Property and Casualty Insurance Companies, China United Property Insurance Company, China Pacific Insurance (Group) Company and China Pingan Property and Casualty Insurance Companies (Pingan) as the research objects, got the result that PICC ( P\&C) has the best performance by using DEA-AHP method to evaluate the enterprise performance, and proposed a strategy that can promote the sustainable development of property insurance companies in China[6]. Singh et al. applied the DEAAHP model to the human resource performance evaluation. Using the integrated data envelopment analysis (DEA), the AHP judgment matrix with local weight selection is generated by pairwise comparison methods. It is used to measure the managers of three different systems at the entry level. It is concluded that the "DEAHP" method has proposed the weight derivation method as substitute of the traditional AHP [7]. Combining with the special situations and actual demands of small and medium enterprises, Liu et al. proposed the performance evaluation model of small and medium enterprises based on DEA and AHP method. AHP method is used to reflect the subjective preference of the evaluator. With the analysis of the judgment matrix, the input and output indexes of the performance evaluation are screened out, and the scientific nature of DEA method is improved when selecting the input and output index. Then, the DEA model is used to solve the efficiency evaluation value, which is implemented by deap2.1 software [8]. Bai et al. used the AHP model to construct the evaluation index system, and DEA model is used to analyze the efficiency of enterprise technological innovation. The differentiation strategy and the innovative radiation pattern of technological innovation region are proposed after researching the regional distribution characteristics of the technological innovation capability of the enterprise [9].

\subsection{Basic steps of operation performance evaluation of municipal wastewater treatment plants by using AHP/DEA evaluation model}

(1) Establish the hierarchical structure of the operation performance of municipal wastewater plants, analyze the relationship between various factors in the operation system of municipal wastewater treatment plant, establish hierarchical structure system. The operation performance evaluation system of the municipal wastewater treatment plant is established at three levels, and the indexes were classified according to the environmental protection performance, resources and energy consumption, technical and economic performance, operational management and key equipment status.

(2) The weight vector $\mathrm{C}:(\mathrm{cl}, \mathrm{c} 2, \mathrm{c3}, \mathrm{c} 4, \mathrm{c5})$ of all factors relative to the total target is calculated by using AHP method.

(3) Establish the decision-making unit

$\mathrm{DMU}_{\mathrm{i}}, \quad(\mathrm{i}=1,2, \ldots, 5)$ according to five indexes in table 1. Use DEA method to calculate the performance value of each decision making unit. The linear planning model of DEA input and output effectiveness of the decision making unit i0 is:

$$
\begin{gathered}
\min \{\theta\} \\
\text { s.t. } \sum_{\mathrm{i}=1}^{\mathrm{n}} \mathrm{X}_{\mathrm{k}}^{(\mathrm{i})} \lambda_{\mathrm{k} j}^{(\mathrm{i})}+\mathrm{S}^{-}=\theta \mathrm{X}^{(\mathrm{io})} \\
\sum_{\mathrm{i}=1}^{\mathrm{n}} \mathrm{Y}_{\mathrm{k}}^{(\mathrm{i})} \lambda_{\mathrm{k}}^{(\mathrm{i})}-\mathrm{S}^{+}=\mathrm{Y}_{\mathrm{j} 0} \\
\lambda \mathrm{k}(\mathrm{i}) \geq 0 ; \quad \mathrm{S}-\geq 0 ; \quad \mathrm{S}+\geq 0 ;
\end{gathered}
$$

Where: $\lambda_{k}{ }^{(i)}$ takes the weight of index $\mathrm{k}$ in $\mathrm{DMU}_{\mathrm{i}}$ unit relative to i0 criterion determined by AHP method, and 
meets the $\sum_{\mathrm{k}}^{\mathrm{ni}} \lambda_{\mathrm{k}}^{(\mathrm{i})}=1$, and calculates the optimal value $h_{i j}$ of the unit effectiveness (the efficiency evaluation index of proposal $\mathrm{j}$ relative to factor $\mathrm{i}$ ).

(4) Using the weights calculated from (2), the overall priority vector $\sigma_{j}=\sum_{i=1}^{5} h_{i j} c_{i}$ is calculated and the compare with $\sigma \mathrm{j}$, and the priority of each proposal can be obtained. The AHP/DEA model for operation performance evaluation of municipal wastewater treatment plants is demonstrated in Fig. 1.

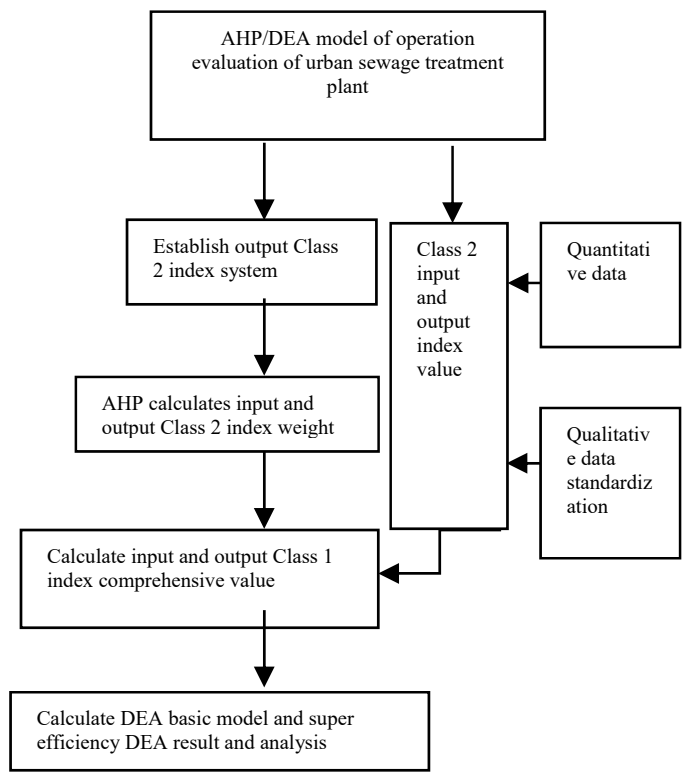

Fig. 1 Basic steps of AHP/DEA comprehensive evaluation method [10]-[12]

\section{Conclusions}

The advantage of AHP/DEA comprehensive evaluation method is to introduce the important factor of decision making relative to the index in the traditional DEA model objective function. It compensates for the defect that DEA method cannot consider the actual importance of the index. The important factor of decision making relative to the index can be solved by using AHP method. The research shows that the calculation process of AHP/DEA model is simple and easy, and it is feasible in the operation performance evaluation of the municipal wastewater treatment plant.

\section{Acknowledgment}

This work was supported by the National Key R\& D Program of China (2017YFF0206702) and Foundation of President of China National Institute of Standardization (542018Y-5926).

\section{References}

1. Zhang Shichang, Zhou Weijie. Value Engineering, 27 (7): 70-73(2008). (in chinese)
2. $\mathrm{Xu}$ Shubo. Analytic hierarchy process (Tianjin University Press, Tianjin, 1987). (in chinese)

3. Chang Jian'e, Jiang Taili. Journal of Wuhan University of Technology (1): 153-156 (2007). (in chinese)

4. Sheng Zhaohan, Zhu Qiao and Wu Guangmou. DEA Theory, Methods and Applications(Science Press, 1996). (in chinese)

5. D.K. Jyoti, S.G. Banwet. International Journal of Productivity and Performance Management, 57 (5): 370-388 (2008).

6. Yang Zhen, Feng Junwen. International Business and Management, (2):92-100 (2014).

7. S. Singh, R. Aggarwal. Journal of the Operations Research Society of China, 2(3): 317-332(2014).

8. Liu Guiqing. Statistics and decision making, (14):173-175 (2013). (in chinese)

9. Bai Yangmin, Peng Yubing, Cui Ting. Statistics and decision making, (12):169-171(2015). (in chinese)

10. Ou Lixiong. Machinery Manufacturing, (7): 1215(2009). (in chinese)

11. Han Haibin, Li Quansheng. Fudan Education Forum, (7): 64-68 (2009). (in chinese)

12. Yang Min. Highway Traffic Science and Technology, (7): 111-115 (2006). (in chinese) 